\title{
LAS RELACIONES MONETARIO-MERCANTILES Y LOS MECANISMOS DE ALIENACIÓN CAPITALISTA EN EL PUEBLO DE AYARANGA, DISTRITO DE PACCHO, PROVINCIA DE HUAURA
}

\author{
COMMODITY-MONEY RELATIONS AND \\ CAPITALIST ALIENATION MECHANISMS IN THE VILLAGE \\ OF AYARANGA, Paccho DISTRICT, PROVINCE HUAURA
}

\author{
Recibido: 21/01/2015 Revisado: 12/04/2015 Aceptado: 16/06/2015
}

\section{Ricardo Bustamante Abad ${ }^{1}$}

¿Qué comportamiento social ha adoptado el pueblo de Colcapampa-Ayaranga, con la siembra de melocotones? ¿Se está perdiendo la Identidad Cultural andina? ¿Qué mecanismos de alienación y enajenación se suscita en la población?

\section{RESUMEN}

Objetivo: Determinar en qué medida los pueblos de Colcapampa-Ayaranga, Huácar dentro de la comprensión del Distrito de Paccho, Provincia de Huaura con la construcción de la carretera y siembra de melocotones y chirimoyas han alterado su comportamiento social y viene siendo ganado por los mecanismos de alienación y enajenación capitalista. Materiales y Métodos: Descriptivo, entrevista, encuesta, etc. Resultado: Históricamente los pueblos de Colcapampa-Ayaranga, Huácar, Paccho se han desarrollado a través de las sociedades desde la comunidad primitiva, tal vez 7000 años a.d.n.e. aún no estudiado con resultado científico, pero hay restos de los "gentiles" que habitaron en cuevas de Tocto y que se habrían alimentado de la caza y la recolección de frutos por cientos de años hasta conocer la agricultura y ganadería. Sembraron maíz, papa, y en cada uno de los pisos altitudinales fueron adoptando diferentes recursos para su alimentación como la mashua, oca. Y domesticaron el cuy que era el alimento de su preferencia y de esta manera fueron forjando su identidad local dentro de los parámetros económicos-sociales. Conclusiones: Los pueblos de Colcapampa-Ayaranga- Paccho y Huácar han ido forjando su desarrollo agrario y también social en su proceso histórico natural de organización en ayllus, que se remontan a cientos de años, cuyo espíritu de ayuda mutua se había mantenido hasta la década de 1960, fecha en que se construye la carretera y la siembra de frutas principalmente los duraznos, y se dio la relación de mercancía-dinero que ha trastornado la economía y el comportamiento de los habitantes, produciéndose la alienación y enajenación.

Palabras clave: Comunidad, circulación monetaria, autárquica, alienación.

\section{ABSTRACT}

Objective: To determine to what extent the people of Colcapampa-Ayaranga, Huácar within understanding Paccho District with the construction of the road and planting peaches and custard apples have altered their social behavior and is being won by the mechanisms of alienation and estrangement capitalist. Materials and Methods: Descriptive, interview, survey, etc. Result: Historically the people of Colcapampa-Ayaranga, Huácar, Paccho have been developed by companies from the primitive community, maybe 7000 years ADNE It not yet studied with scientific result, but no trace of the "gentiles" who lived in caves Tocto and that would have been fed by hunting and gathering fruit for hundreds of years to make agriculture and livestock. They planted corn, potatoes, and in each of the altitudes were taking different resources for food such as nasturtiums, goose. And it was domesticated guinea pig food of your choice and thus were forging their local identity within the economic and social parameters. Conclusions: The peoples of Colcapampa-Ayaranga- Huácar Paccho and have forged their agricultural development and social in their natural historical process of organization in ayllus, dating back hundreds of years, the spirit of mutual aid was maintained until the decade 1960, when the road and planting fruit mainly peaches is built, and the relationship of commodity-money that has disrupted the economy and the behavior of the inhabitants were given, resulting in alienation and alienation.

Keywords: Community monetary circulation, autarchic, alienation.

\section{INTRODUCCIÓN}

Hasta la década de 1950, el pueblo de la comunidad de Colcapampa-Ayaranga, continuaba con la práctica cotidiana de sus quehaceres ancestrales en la siembra de maíz, papa, habas, trigo y su comportamiento social era de solidaridad, ayuda mutua, no le daban importancia al dinero, sus excedentes agrarios lo realizaban a través del intercambio, principalmente en los meses de agosto-setiembre que viene a ser la temporada de la cosecha, y Colcapampa-Ayaranga adquirió fama en el contexto regional e interregional con la producción de maíz dulce, que llegaban al pueblo, comunidades vecinas y hasta de lugares lejanos con caballos, burros y llamas portando ollas, cántaros de arcilla, frazadas, ponchos, sogas, chumpi, faldas, cinta peruana, telas, sortijas, aretes, charqui de alpaca; y esta operación la mantuvieron desde épocas ancestrales que los huachanos también llevaban pescado seco para intercambiar y proveerse de maíz, habas, etc. 


\section{Vicerrectorado de Investigación}

\section{Bovist: Big Bang Faustiniano}

Era un pueblo dedicado a la agricultura y ganadería, profundamente católico y que celebraban las festividades religiosas de San Pablo, María Magdalena, siendo la más importante que congregaba multitudes la "Bajada de Reyes" en la que todos sin excepción degustaban la gastronomía típica de Chase, Pachamanca, Fojay, Cashqui, Humitas, Sango y saboreaban la chicha huarambera y bailaban en rueda con sus gestos y movimientos rítmicos al son del arpa, el clarín y la guitarra.

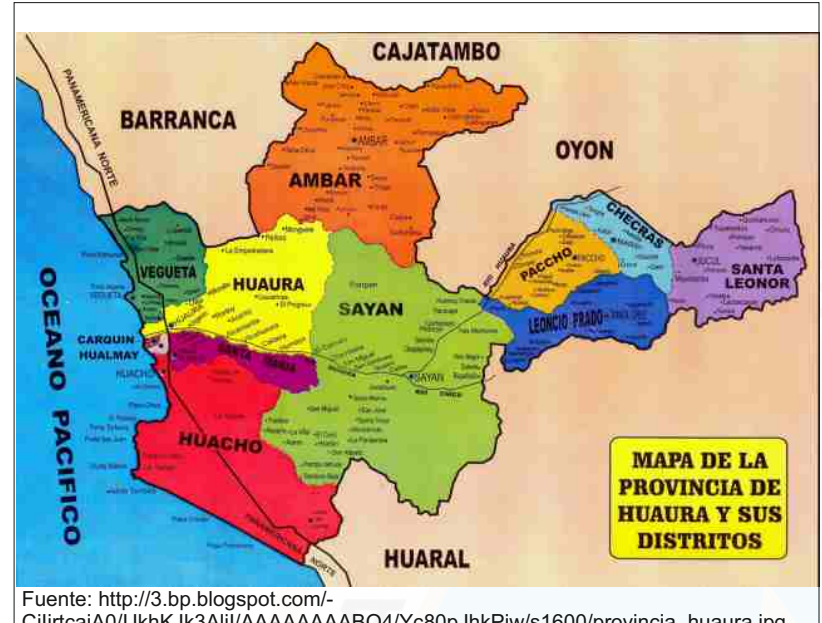

Figura 1. Mapa de la Provincia de Huaura

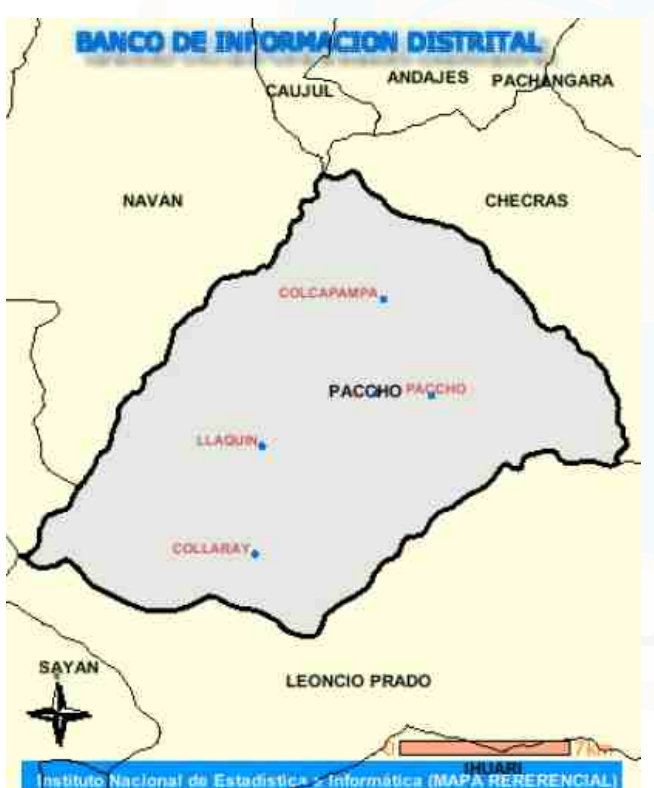

Fuente: http://www.map-peru.com/mapa/Lima/513_huaura-paccho.png

Figura 2. Mapa del Distrito de Paccho

\section{EI Ayllu legado social y laboral}

El ayllu, ese legado precioso del pasado lo conservaron y afianzaron los de Colcapampa-Ayaranga. Ahora bien, en el pueblo no sólo había una familia sino varios, y a todos sus integrantes se les tenía como familiares directos. Pero, a quienes llegaban con posterioridad al pueblo, también se les consideraba como familia, Torero (2002).

\section{¿Cómo era practicado la socialización del trabajo?}

En Colcapampa-Ayaranga, el trabajo social o cooperativo se hacía en la forma de la ayuda mutua. A tal ayuda mutua entre los familiares más cercanos se les denominaba YANAPACUY. Macera (1985) lo define como ayuda mutua voluntaria, ella se apresta le ofrece sin esperar ninguna retribución monetaria. De hecho es la cooperación fraterna y desinteresada, que estaban obligados a ofrecerse los familiares próximos.

Pero también funcionó la AICHAMA, que significaba la cooperación en trabajo entre los distintos grupos de familias el que consistía un intercambio recíproco y equivalente de trabajo entre unos y otros (Silva, 1980). Todo esto se llevaba a cabo luego de la previa ejecución de ciertas ceremonias o ritos de permialización, consistente en que unos piden a los otros que los ayuden en sus actividades por ejemplo en la siembra o cosecha de sus chácras con el compromiso de que les ofrecerán buena comida y bebida, amén del compromiso de que, en su momento, les retribuirán también con su trabajo y esfuerzo igual o equivalente. No se hablaba de dinero y así se condujo hasta los años de 1960.

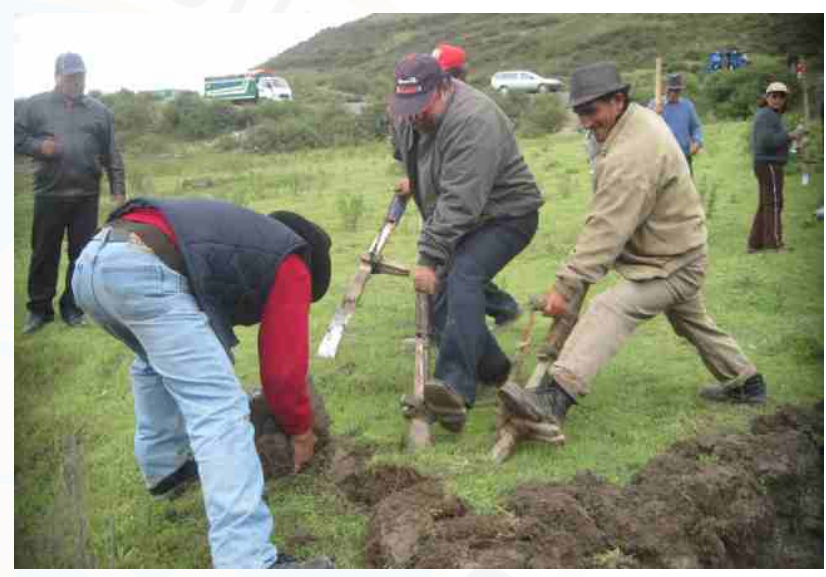

Fuente: http://www.manufactoria.info/wp-content/uploads/2014/02/Campo-3.jpg

Figura 3. Las faenas comunales de los ayllus era una costumbre ancestral de los comuneros de Paccho

Construcción de la carretera de penetración Paccho Tingo-Colcapampa-Ayaranga-Huácar-Paccho e inicios de las relaciones monetario mercantiles

La construcción de la carretera se dio inicio en los años de 1965, bajo la gestión de las autoridades de los pueblos de Ayaranga, Huácar y Paccho se hizo realidad con el esfuerzo de los mismos comuneros, aunque el gobierno de Fernando Belaúnde Terry, bajo el Programa de Cooperación popular, proporcionó a los comuneros: catarpilas, dinamita, lampas, picos, barretas, etc.

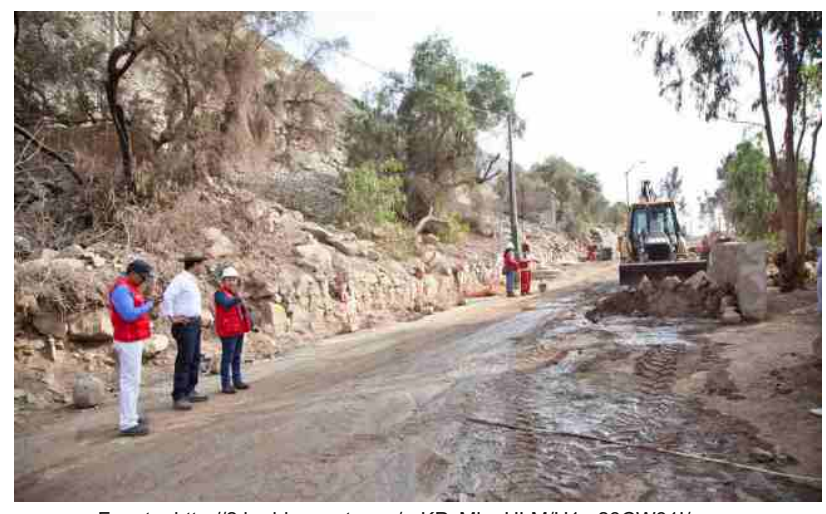

Fuente: http://2.bp.blogspot.com/-nKPzMiogHLM/U1rs23CW31// AAAAAAAAF2k/OfRILscMz2E/s1600/IMG_5118.jpg

Figura 4. La construcción de la Carretera hacia el Distrito de Paccho se hizo realidad durante el gobierno de Belaúnde 
Hasta ese entonces algunos comuneros acomodados se dedicaron a la crianza de ganado vacuno y debido a la benignidad del clima y el medio geográfico se impulsó el cultivo de alfalfa que eran arrendados en renta dinero a los ganaderos del lugar que engordaban a los torillos y luego de un determinado tiempo los vendían en los camales de Sayán y Huacho, generándole un excedente de utilidad en beneficio del ganadero.

$\mathrm{La}$ actividad ganadera paulatinamente fue perdiendo su influencia económica, ya que determinadas capas sociales dedicados a la producción agraria de subsistencia iban reemplazándola por la siembra de melocotones, chirimoya, manzana, etc. Sin embargo hay comuneros que realizan actividades simultáneas de agricultores y crianderos de característica extensiva de ganado vacuno que la gran mayoría de comuneros lo practicaban tanto de Status social medio y pobre.

Hasta el año 1970-1980 los comuneros cosechaban maíz, trigo, habas y que construían eras en sus casas, que con 20 o 30 acémilas trasladaban de sus chácras mazorcas de maíz y los hacían secar, lo desgranaban y solían guardar en ollas grandes y recipientes de gran tamaño y sacaban medido los productos para su alimentación diaria. Era una economía autárquica que practicaban desde tiempos inmemoriales.

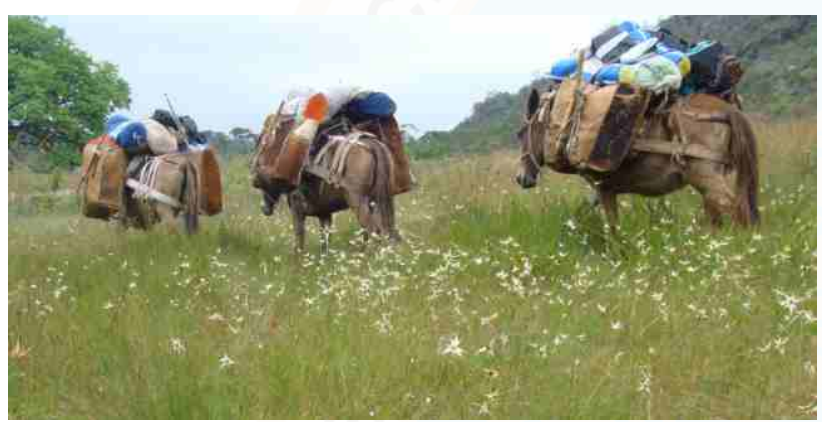

Fuente: http://static.panoramio.com/photos/large/28111958.jpg

Figura 5. Los comuneros de Colcapampa-Ayaranga utilizaban acémilas para trasladar sus productos agrícolas

El 29 de agosto era la fiesta tradicional del pueblo en la que se celebraba la festividad de Santa Rosa de Lima, cabe señalar que esta festividad en los últimos años ha ido perdiendo su tradición, ya que en sus buenos tiempos el mayordomo solía desplegar todo un acontecimiento que concentraba a la gran mayoría que inclusive venían pueblos vecinos con sus elegantes trajes de Cordellate, finos brazaletes de oro y plata, y se involucraba a la festividad donde bailaban y se deleitaban con la gastronomía del lugar que no le costaba ningún centavo a la concurrencia, todos disfrutaban de la fiesta por cuatro días con abundante comida, chicha "Huarambera" y ron de Andahuasi.

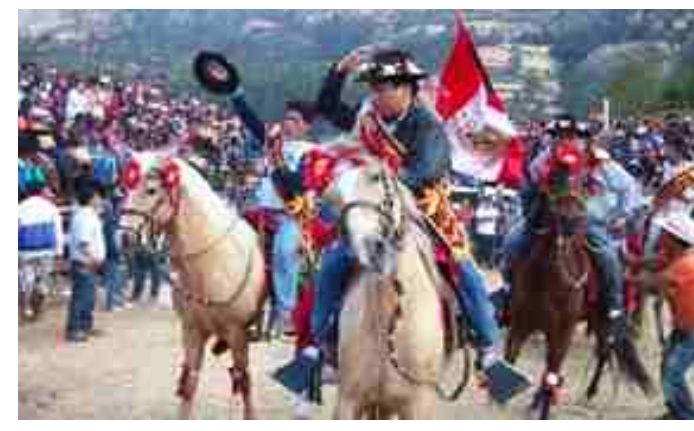

Fuente: http://i.ytimg.com/vi/UQUwiMXN9ys/hqdefault.jpg

Figura 6. La celebración de la fiesta de Santa Rosa de Lima era una costumbre en el pueblo de Colcapampa-Ayaranga
En la tarde del día central se organizaba la procesión que se desplazaban por las principales calles del pueblo de Ayaranga acompañado del numeroso séquito y que recibía muestras de cariño con ofrendas de maíz, papa, queso, charqui, y hasta billetes de cien soles.

En algunos momentos los comuneros bailaban al son de la banda con vistosos vestidos llenos de encanto y multicolor, también se desplazaban las pallas y vírgenes en bailes de corrido al son de cohetes y cohetones.

Sin embargo estas tradicionales fiestas han ido perdiendo su colorido costumbrista por la llegada de otros grupos religiosos de evangelistas y testigos de Jehová, Pentecostés que han cuestionado la religión católica de adorar santos de yeso y madera, y en su lugar han captado fieles que ahora se reúnen los sábados, perdiéndose un valioso capital cultural que bien podía significar el turismo.

Los días 8 y 9 de setiembre es la fiesta de rodeo que se dan cita todos los comuneros tanto de las capas sociales medios y crianderos ricos, cuya fiesta consiste en señalar con un fierro caliente con las iniciales de su propietario en la paletilla derecha del ganado vacuno. En ese sentido la mayoría se reúnen en la noche con sus familias, realizan la catipada con coca y cal, saborean abundante chicha y celebran con canciones alusivas a la vaca, el toro, a la majada, a los cerros al son de una tinya pequeña, otros que tienen mayor posibilidad económica celebran al son de un clarinete, saxo, piano y acompañado de cohetes y cuetones.

Los crianderos bailan y se desplazan por las calles arrojando confites, caramelos, galletas en dirección al coz de la comunidad donde los animales son señalados con cintas multicolor que se ponen a las terneras y a las vacas madres, es muy posible que esta festividad fue instituida en la colonia, aún se sigue manteniendo en la actualidad, aunque no con esa emoción y singularidad de antes que llegara la carretera (Retuerto, 2012).

La fiesta de la Bajada de Reyes es la más concurrida, se realiza todos los años los días 5,6,7 y 8 de enero, la más pomposa y mercantil de todas las fiestas, pues el caporal contrata a los cantantes de la cartelera profesional que opera en Huacho o Lima, que puede costar entre 8 a 10 mil dólares, en la que la comunidad de toda edad, así como visitantes de pueblos cercanos se dan cita en el galpón para bailar con sus parejas a cambio de consumir gaseosa, cerveza, atún, fruta.

Así mismo pueden degustar de lomo, churrasco, arroz chaufa, cau-cau, que son atendidos por chefs y cimbreantes damas contratadas por el caporal, cuyo precio oscila desde 15 a 20 soles cada plato. En esta fiesta todo es pagado hasta la chicha Huarambera. Hay competencias deportivas de asociaciones y clubes de pueblos que cotizan su participación en soles y dólares, y en todas esas actividades circulan cajas de cerveza que al término de la fiesta de 4 días con el "despachalashon" se suma de 400 a 500 cajas.

Otra muestra de las relaciones monetariomercantiles es el comercio basado en productos eléctricos como cocina a gas, radio, celulares, DVD, televisión, refrigeradoras, tablet, también productos agrícolas como úrea, insecticidas, fumigadoras, etc. Cada comunero ostenta la adquisición de motos lineales, mototaxi, camiones, autos, camionetas $4 \times 4$.

Asimismo, algunos comuneros en sus propias casas han instalado tiendas comerciales y que venden: arroz, fideos, azúcar, cerveza, útiles escolares como lapiceros, plumones, papelote, aunque no suele dedicarse exclusivamente a dicha actividad, siempre alternan con siembra de melocotones, chirimoyas y también la ganadería, etc. 


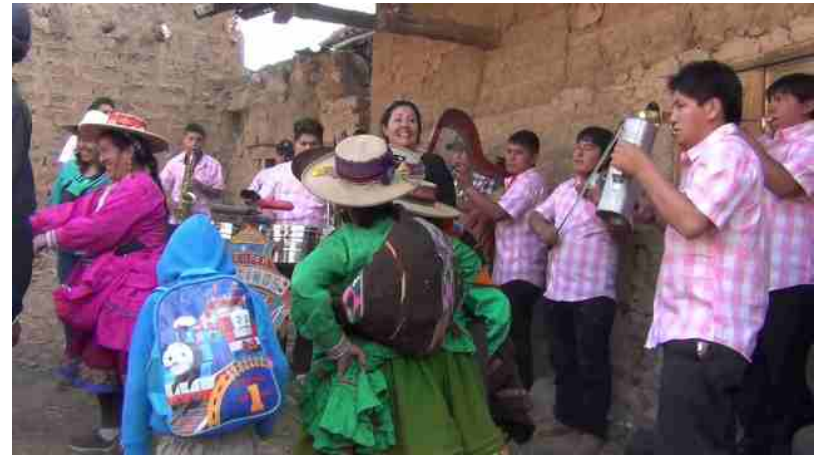

Fuente: http://i.ytimg.com/vi/-6cW6qnRINg/maxresdefault.jpg

Figura 7. La fiesta de la Bajada de Reyes en Colcapampa-Ayaranga fomenta el turismo

Intensificación de las relaciones monetario mercantiles y la alienación y enajenación económica y cultural

El pueblo de Colcapampa-Ayaranga, su origen se pierde en la más remota antigüedad y su formación económico social se ha desarrollado dentro del cauce de la solidaridad, de la ayuda mutua y ha conservado sus tradiciones milenarias tanto económicos, políticos, sociales y culturales dentro de los parámetros de la nacionalidad peruana, pero esta realidad ha trastocado por agentes alienantes desde la construcción de la carretera que día a día viene intensificándose con tabla de valores y relaciones monetario mercantilista muy propio del sistema capitalista (Romano, 2008).

\section{MATERIALES Y MÉTODOS}

La investigación se realizó en una muestra estratificada de 50 personas entre ciudadanos e hijos residentes del pueblo de Ayaranga en Huacho-Huaura, 20 hombres y 30 mujeres, todos ellos con instrucción primaria y secundaria, para unificar nuestra investigación en proceso de recolección, análisis y vinculación de datos cuantitativos y cualitativos en un mismo estudio, se utilizó el enfoque mixto. Se utilizó también la estadística descriptiva básica y se realizaron comparaciones para describir las variables cuantitativas.

\section{RESULTADOS}

Tabla 1. Distribución porcentual, de si se está perdiendo la identidad cultural del pueblo de Colcapampa-Ayaranga

\begin{tabular}{|c|c|c|c|c|c|c|c|c|c|c|c|c|c|}
\hline \multirow[t]{2}{*}{ ÍTEM } & \multirow[t]{2}{*}{ VE } & \multicolumn{2}{|r|}{1} & \multicolumn{2}{|c|}{2} & \multicolumn{2}{|c|}{3} & \multicolumn{2}{|c|}{4} & \multicolumn{2}{|r|}{5} & \multicolumn{2}{|c|}{6} \\
\hline & & $F$ & $\%$ & $F$ & $\%$ & $F$ & $\%$ & $F$ & $\%$ & $F$ & $\%$ & $F$ & $\%$ \\
\hline sí & 4 & 4 & 13,33 & 3 & 10,00 & 18 & 60,00 & 4 & 13,3 & 2 & 6,66 & 2 & 6,6 \\
\hline UN POCO & 3 & 20 & 66,76 & 24 & 80,00 & 8 & 26,86 & 16 & 53,43 & 21 & 70,00 & 23 & 76,76 \\
\hline CASI NADA & 2 & 3 & 10,00 & 1 & 3,43 & 2 & 6,6 & 6 & 20,00 & 7 & 23,43 & 4 & 15,3 \\
\hline NO & 1 & 3 & 10,00 & 2 & 6,66 & 2 & 6,6 & 4 & 13,33 & - & - & 1 & 3,33 \\
\hline TOTAL & 10 & 30 & 100,00 & 30 & 100,00 & 30 & 100,00 & 30 & 100,00 & 30 & 100,00 & 30 & 100,00 \\
\hline
\end{tabular}

Fuente: Elaboración propia

Tabla 2. Revaloración de conocimientos, cultura y ecología ancestral

\begin{tabular}{lr}
\hline ÍTEM & $\%$ \\
\hline Muy necesario & 65 \\
Necesario & 20 \\
Poco necesario & 10 \\
Inncesario & 5 \\
\hline
\end{tabular}

Fuente: Elaboración propia

Se entrevistaron a un total de 30 mujeres ayaranguinas residentes en Huacho-Huaura, para conocer si tenían conocimiento sobre los cambios económicos, políticos, sociales y culturales-ecológicos que se han operado en el pueblo de Ayaranga a raíz de la construcción de la carretera y el cultivo de melocotones y chirimoya.

El porcentaje de los grupos entrevistados son $6,66 \%$ si conoce, el $76,76 \%$ un poco de conocimiento que se viene operando en Colcapampa-Ayaranga, el 13,33\% casi nada, y el 3,33\% nada.

Se entrevistaron a un total de 20 hombres de hijos residentes ayaranguinos en Huaura- Huacho, para indagar que si es necesario revalorar los conocimientos, cultura y ecología de los antiguos habitantes de ColcapampaAyaranga. El porcentaje de los grupos entrevistados son el $65 \%$ consideran muy necesario, el $20 \%$ necesario, el $10 \%$ poco necesario y el $5 \%$ innecesario.

\section{DISCUSIÓN}

1. La comunidad de Colcapampa-Ayaranga comprensión del Distrito de Paccho, Provincia de Huaura y la Región Lima se desarrolló presumiblemente hace 7000 años a.d.n.e., y ha iido estructurando su proceso histórico natural, constituyendo aspectos económicos, políticos, sociales, culturales y ecológicos en forma inédita en relación con los pueblos vecinos.

2. Colcapampa-Ayaranga solucionó sus problemas socio-económicos a través de su propia práctica, su expresión técnica y ecológica, a través de su desarrollo histórico.

3. La estructura económico-social de ColcapampaAyaranga tuvo su propia particularidad por cuanto a los antiguos pobladores fueron básicamente agricultores por la benignidad climática y de la diversidad de los sistemas ecológicos que presenta la geografía se dedicaron a la siembra del maíz y la papa. 


\section{Rovista Big Bang Faustiniano}

\section{Vicerrectorado de Investigación}

En la perspectiva histórica la comunidad primitiva Colcapampa-Ayaranga fue colectivista y recíproca, practicaron la ayuda mutua y con la práctica cotidiana cohesionó a todos sus miembros integrantes de los diferentes ayllus teniendo como su Apu al cerro Quichunque.

Esta comunidad ha recibido influencia supraestructural política y religiosa a la llegada de los españoles que plasmaron los evangelizadores y que mandaron construir una iglesia que conserva los dibujos y escenas propias de santos y vírgenes de la época (Rosas, 1976).

La construcción de la carretera Paccho TingoColcapampa-Ayaranga ha producido ciertos cambios económicos, sociales, culturales y ecológicos que se expresa en las relaciones monetario-mercantiles con la siembra de melocotones, chirimoyas, cuyas ganancias han generado cambios económicos y que se expresa en la compra de motos lineales, autos, camiones $4 \times 4$, cocina a gas, refrigeradoras, televisor a color plasma, celulares, tablet, DVD, etc., que ahora ven canales de televisión no solamente nacionales, sino de otros países como México, Colombia, España, etc., ésta práctica está generando alienación cultural (Romano, 2008).

Así mismo, ha cambiado su conducta social que ahora muestran mayor egoísmo e individualismo frente a la práctica social de ayuda mutua que por miles de años fue preponderante el ayllu, enajenándose paulatinamente.

La nueva generación de fruteros ha dado paso a la alimentación chatarra y bebidas de frugos, pulpín, coca cola, inca Kola, ya no siembran los alimentos tradicionales basados en papa, maíz, etc., y se comía el chase, lagüita, sango, cashqui, etc.

El excesivo uso de pesticidas y abonos artificiales como la práctica capitalista en la agricultura, es prioritaria la ganancia, lo que está generando cambios ecológicos, contribuyendo a la destrucción del ecosistema y generando el calentamiento global.

\section{Recomendaciones}

Continuar con la investigación, análisis e interpretación sobre los orígenes milenarios del pueblo de Colcapampa- Ayaranga que tuvo su escenario en la región Noreste del Perú.

Colcapampa-Ayaranga debe revalorar el conocimiento de sus antepasados en la experiencia y manejo de la biodiversidad que hizo una cuantiosa producción de maíz y papa con abono orgánico sin atentar su geografía y su ecosistema.

Revalorar sus costumbres y cultura ancestral de sus fiestas, creencias etnográficas para desarrollar proyectos sustentables del turismo.

\section{REFERENCIAS BIBLIOGRÁFICAS}

Macera, P. (1982). Historia del Perú. Lima.

Retuerto, F. (2012). Monografía del Pueblo de Ayaranga. Inédito.

Romano, V. (2008). La Formación de la Mentalidad Sumisa. México.

Rosas, C. (1976). La Provincia de Chancay y la Emancipación. Lima.

Silva, F. (1982). Historia del Perú. Tomo I. Lima.

Torero Fernández de Córdoba. (2002). Idioma de los Andes, Lingüística e Historia. Lima.

Villa, P. (1935). Las Culturas Prehispánicas del Departamento de Lima. Lima.

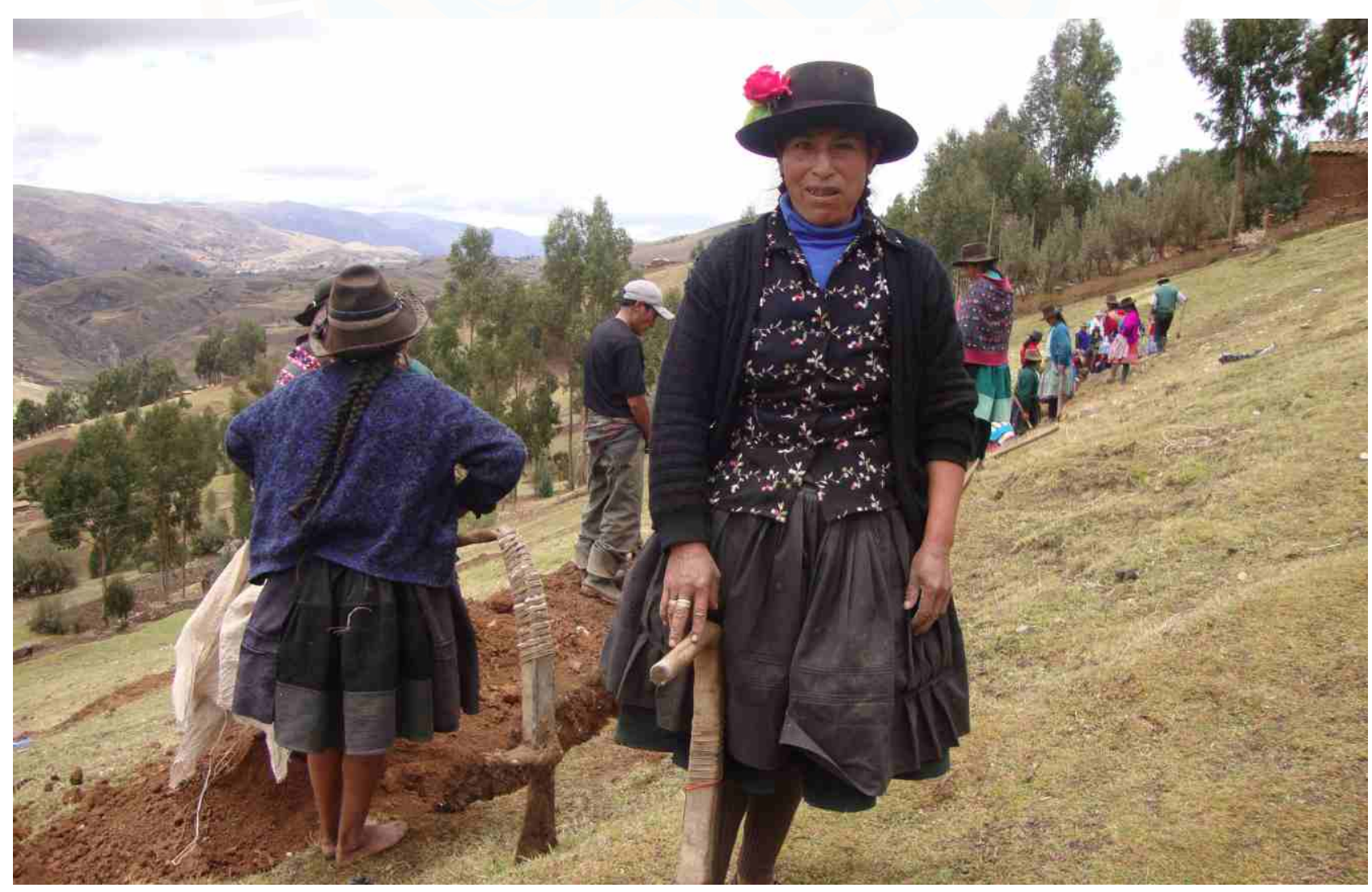

Fuente: http://ipsnoticias.net/fotos/MarinaHuamani_MilagrosSalazar_IPS.jpg

Figura 8. En Colcapampa-Ayaranga, el trabajo social o cooperativo se hacía en la forma de la ayuda mutua 